\title{
A Study of the Incidence of Coccygeal and Lumbar Sacralisation and its Clinical Significance
}

\author{
Jefferson Pereira Sarmento, ${ }^{1}$ Diego Furtado Rolim Lima, ${ }^{1}$ Ana Priscila Franca Correia, ${ }^{1}$ Vagner da Fonseca Conca Filho, ${ }^{2}$ \\ Israel Rodrigues Pereira, ${ }^{3}$ Cecília de Lima Leite, ${ }^{1}$ Samara Alves Brito, ${ }^{1}$ Jalles Dantas de Lucena ${ }^{1}$ \\ ${ }^{1}$ Medicine Course, College Santa Maria, Cajazeiras, PB, Brazil. \\ ${ }^{2}$ Medicine Course, Faculty of Medicine Nova Esperança, João Pessoa, PB, Brazil \\ ${ }^{3}$ Medicine Course, Federal University of Ceará, Faculty of Medicine, Department of Morphology, Fortaleza, CE, Brazil
}

Disclose and conflicts of interest: none to be declared by all authors

\section{ABSTRACT}

Introduction: the sacrum is formed by the fusion of five vertebrae. It usually has four pairs of foramina that represents the exit point of the sacral nerves. A sacrum with five pairs of foramina is an anatomical variant resulting from sacralisation of a lumbar vertebra at the base of sacrum or sacralisation of coccygeal vertebra at the apex of the sacrum. Thus, the occurrence of these anatomical variants can develop complications such as lumbar pain, early degeneration of the intervertebral disc and lumbar spine diseases. The objective of the present study was to know the incidence and types of sacralisation of the fifth lumbar vertebra and the first coccygeal vertebra, and its clinical significance.

Material and Methods: in the present study, 48 adult human sacrum were examined in the Human Anatomy Laboratory of the Federal University of Ceará and the Medical School Nova Esperança, Brazil. The sacralisation of the fifth lumbar vertebra and of first sacral vertebra was described according to the Singh classification.

Results: about the 48 sacrum examined, 33 (68.75\%) were normal and 15 (31.25\%) presented sacralisation. Those with sacralisation of fifth lumbar vertebra were 12 cases (25.0\%), all cases of Type I, and 3 cases of sacralisation first coccygeal vertebra (6.25\%), all of Type III.

Conclusion: the high numbers of sacralization of the lumbar vertebra diverging from data found in the literature.

Keywords: Anatomy; Coccygeal sacralisation; Lumbar sacralisation; Sacrum.

\section{Introduction}

Normal sacrum is formed by fusion of five sacral vertebrae creating four pairs of sacral foramina which transmit anterior and posterior branches of the spinal nerves, respectively ${ }^{1}$. Most anatomical variations in the lumbosacral region are associated with differences in the sacral vertebrae or sacral foramina pairs number, caused either by the fusion of the fifth lumbar or the first coccygeal vertebra with the sacrum².

Occurrence of five pairs of sacral foramina is an anatomical variant which is generated due to inclusion of an extra vertebra either at the base or at the apex of sacrum. At the base of the sacrum there may be fusion of fifth lumbar vertebra with the first sacral vertebra resulting in sacralisation of lumbar vertebra. When the L5 vertebra is completely fused to the sacrum, the lumbar spine is consisted of four vertebrae and six vertebrae constitute the sacrum ${ }^{2,3}$. Similarly at the apex of sacrum, there may be fusion of first coccygeal vertebra with the fifth sacral vertebra which is known as sacralisation of coccygeal vertebra. Therefore, addition of a vertebra to sacral region is always accompanied with the loss of vertebra from lumbar or coccygeal region ${ }^{1}$.
There are reports of numerous anatomical variations of the sacrum, which include the formation of six pairs of sacral foramina. This may be outcome of fusion of fifth lumbar vertebra at the base of sacrum and coccygeal vertebra at the apex of sacrum. These seven vertebrae create six pairs of sacral foramina ${ }^{1}$. On the other hand, the occurrence of three sacral foramina pairs develops due to failure of fusion of the first sacral vertebra, which is known as lumbarization ${ }^{2}$.

Due to sacralisation of lumbar vertebra there could be difficulty in numbering the vertebrae and herniation of disc above sacralisation, associated with back pain and fifth sacral nerve may be compressed leading to sciatica $^{1,4}$. The fifth lumbar vertebra transmits the weight of upper trunk of human body. Therefore, may present various secondary pathological conditions of the spine due to the mechanical alterations of the area, such as spinal canal or foraminal stenosis, intervertebral disc herniation and facet joint degeneration and arthrosis ${ }^{5,6,7}$. Sacralisation of coccygeal vertebra may cause coccydynia, caudal block failure, difficult second stage of labour and perineal tear ${ }^{1}$.

The knowledge of anatomical divergences and mechanical changes of lumbosacral region is of 
paramount importance to physicians, surgeons and obstetricians. In addition to this, there is paucity of studies on sacralisation of coccygeal vertebra. Thus, the present study was carried out to know the incidence/frequency and type of sacralisation of the fifth lumbar vertebra and the first coccygeal vertebra, and its clinical significance.

\section{Materials and Methods}

In the present study 48 adult human sacrum from individuals from Northeast Brazil, belonging to the Human Anatomy Laboratory of the Federal University of Ceará and Medical School Nova Esperança were analyzed. Damaged and pathological sacrum were excluded from this study.

Data was collected by naked eye observation for different types of sacralisation of fifth lumbar vertebra and the first sacral vertebra, depending on fusion (complete and incomplete) and right or left side sacralisation.

The sacralisation of the fifth lumbar vertebra and of the first sacral vertebra was described according to the Singh ${ }^{1}$ classification. This classification was grouped in two types of lumbar sacralisation and three types coccygeal sacralization, totaling to five categories.

\section{Lumbar sacralisation:}

Type I - Sacrum with complete lumbar sacralisation. Complete fusion of fifth lumbar vertebra with first sacral vertebra.

Type II - Sacrum with incomplete lumbar sacralisation. Incomplete fusion between body of fifth lumbar vertebra and first sacral vertebra.

\section{Coccygeal sacralisation:}

Type III - Sacrum with complete coccygeal sacralisation (dorsal surface). Complete fusion of body, transverse process and cornua of first coccygeal vertebra with corresponding elements of fifth sacral vertebra.

Type IV - Sacrum with incomplete coccygeal sacralisation (dorsal surface). Fusion of body and transverse process of the first coccygeal vertebra with apex and the inferior lateral angle of sacrum, respectively, but without fusion between cornua of first coccygeal vertebra and sacral cornua.

Type V - Sacrum with incomplete coccygeal sacralisation (dorsal surface). Fusion of body and cornua of the first coccygeal vertebra with apex and the cornua of sacrum, respectively, but without fusion between transverse process of first coccygeal vertebra and the inferior lateral angle of sacrum, not forming the fifth pair of sacral foramina laterally. The results were showed with descriptive statistics.

\section{Results}

A total of 48 adult human sacrum were examined in this study, out of which 33 sacrum (68.75\%) were found normal, having five vertebrae constituting four pairs of sacral foramina, and the remaining 15 (31.25\%) having anatomical variations of sacralisation (Table 1).

Table 1. Presence of sacralisation in fifth lumbar vertebra and first coccygeal vertebra.

\begin{tabular}{l|c|c}
\hline \multicolumn{1}{c|}{ Sacralisation } & Frequency & Percent (\%) \\
\hline Not (Normal) & 33 & 68.75 \\
\hline Fifth lumbar vertebra & 12 & 25.00 \\
\hline First coccygeal vertebra & 3 & 6.25 \\
\hline Total & 48 & 100.00 \\
\hline
\end{tabular}

Twelve cases (25.00\%) of sacralisation of fifth lumbar vertebra were found. All cases were classified as Type I (Table 2), with complete fusion between fifth lumbar vertebra and the first sacral vertebra, and bilateral fusion of transverse processes of fifth lumbar vertebra to ala of sacrum. Further, those with sacralisation of first coccygeal vertebra were detected in three cases (6.25\%), all cases were classified as Type III (Table 3), with fusion of the body, transverse process and the cornua of first coccygeal vertebra with corresponding elements of the sacrum. The other types were not observed.

Table 2. Type of sacralisation of fifth lumbar vertebra.

\begin{tabular}{l|c|c}
\hline \multicolumn{1}{c|}{ Type of sacralisation } & Frequency & Percent (\%) \\
\hline Type I (Complete) & 12 & 25.0 \\
\hline Type II (Incomplete) & 0 & 0 \\
\hline Total & 12 & 25.0 \\
\hline
\end{tabular}

Table 3. Type of sacralisation of first coccygeal vertebra.

\begin{tabular}{l|c|c}
\hline Type of sacralisation & Frequency & Percent (\%) \\
\hline Type III (Complete) & 3 & 6.25 \\
\hline Type IV (Incomplete) & 0 & 0.00 \\
\hline Type V (Incomplete) & 0 & 0.00 \\
\hline Total & 3 & 6.25 \\
\hline
\end{tabular}

Further, 46 sacrum (95.8\%) showed the complete sacral canal and seven sacrum (14.6\%) showed osteophytes in one or more of their segments.

\section{Discussion}

Lumbosacral transitional vertebrae (LSTV) are congenital anomalies of the lumbosacral region which includes lumbarization and sacralisation ${ }^{8,9,10}$, observed for the first time by Bertolotti ${ }^{11}$. The interpopulation prevalence of this anomaly varies greatly in the international literature, ranging from $4.00 \%$ to over $35.00 \%{ }^{5,9,12}$. In the present study, we observed an incidence of sacralisation of fifth lumbar vertebra of $25.00 \%$. All of them are type I sacralisations with complete fusion of fifth lumbar vertebra with first sacral vertebra. In Brazil, Rizzi et al. ${ }^{13}$ analyzed 79 
sacrum and found no cases of sacralization of lumbar vertebra. In 2018, Macêdo ${ }^{14}$ found lumbar sacralisation in $5.21 \%$ at 115 sacrum studied. Both studies did not analyze the type of sacralization of the fifth lumbar vertebra.

The incidence in our study was comparable to the numbers of international studies by Laishram et al..$^{15}$ which analyzed 155 sacrum and found sacralisation of lumbar vertebra in $23.22 \%$. However, the incidence was much higher than the studies of Goswami et al. ${ }^{16} 2.50 \%$, Chaijaroonkhanarar et al. ${ }^{17} 4.40 \%$, Krishnamurthy and Adibatti ${ }^{6}$ 6.00\%, Swargam and Chandrupatla ${ }^{18} 10 \%$.

Most people with sacralisation are born with it ${ }^{1}$. Breathnach $^{19}$, Sadler ${ }^{20}$ and Sharma et al. ${ }^{21}$ showed that vertebrae are developmentally derived from the sclerotomes of the somites. Embryologically, the vertebra during developmental process receives contribution from the caudal half of one sclerotome and from the cranial half of succeeding sclerotome. Sacralisation and lumbarisation are caused by the border shifts. Sacralisation of fifth lumbar vertebra is due to cranial shift and the lumbarisation of first sacral segment is due to caudal shift.

The sacralisation can also be attributed to the dependency of the sacral morphology to the load related fusion of the bone structure as it helps in the transmission of weight to lower extremity ${ }^{22}$. Wellik and $\mathrm{Capechi}^{23}$ reported genetic factors implicated in the development of transitional vertebra when mutations in the Hox10 and Hox11 genes can alter the normal pattern of lumbar and sacral vertebra leading to lumbosacral transition vertebrae. They showed that in the absence of Hox11 function, sacral vertebrae are not formed and instead these vertebrae assume a lumbar identity. In addition, they showed that in the absence of Hox-10 function, no lumbar vertebrae are formed.

Other less common reasons of sacralisation include trauma with vertebral column injury, extreme arthritic changes and purposeful spinal fusion surgery ${ }^{1}$.

The sacralisation of fifth lumbar vertebra is clinically very well debated. Due to fusion of fifth lumbar vertebra to sacrum, fifth sacral nerve may be compressed resulting in sciatica and back pain ${ }^{1}$. Eyo et $a . .^{24}$ reported that $50.00 \%$ of patients with LSTV may have low back pain.

In the lumbar sacralisation, the weight transmission of trunk of human body starts from sacralised first sacral vertebra (L5) whereas transmission is executed by last lumbar vertebra which in this case is fourth. This creates a change of the gravity center, putting many anatomical structures under stress which may create multi-fold pathological problems such as irritation of surrounding structures which may be caused during rotation, forward/backward and lateral movement of trunk ${ }^{1}$.

Presence of sacralisation L5 may create difficulty in identifying the lumbar level corresponding to a nerve root at the time of spinal block ${ }^{1}$. Thus, a radiologic examination must be performed when sacralised L5 vertebra is suspected before a lumbar epidural injection or nerve root block to prevent any intra-operative confusion over level identification of vertebra ${ }^{25}$. There are reports of surgeries being performed at the wrong lumbar level ${ }^{26}$ and the presence of a transitional vertebra may contribute to this error.

There was also observed that the lumbosacral intervertebral disc is significantly narrowed ${ }^{27,28}$, patients with LSTV are reported to have increased risk for advanced disc degeneration or disc herniation ${ }^{4,9,29,30}$ and can occur even at young ${ }^{4}$.

Sacralisation of first coccygeal vertebra was present in $6.25 \%$ of cases. This anatomical variation occurred through the complete fusion of body, transverse process and cornua of first coccygeal vertebra with the corresponding structures of the last sacral vertebra (Type III). The fifth sacral foramina pair is formed from the sacralisation of coccygeal vertebra), that transmits the fifth sacral nerve and coccygeal nerve ${ }^{1}$. According to Singh ${ }^{1}$, the cause for this process to occur is generally congenital and, on a smaller number, due to traumatic injuries, surgeries or changes resulting from age.

Regarding sacralisation of coccygeal vertebra, there is little available data in the literature. In Brazil, Rizzi et al. ${ }^{13}$ and Macêdo ${ }^{14}$ did not analyze the presence of sacralisation of coccygeal vertebra in their studies. In Indian, Singh ${ }^{1}$ has reported an incidence of $13.60 \%$.

Clinically, caudal anaesthesia is employed for providing post-operative analgesia after genitourinary, lower abdomen and lower limb operations. In absence of knowledge of coccygeal sacralisation, there may be nerve block failure or inadequate analgesia after surgical procedures ${ }^{15,31,32}$. In addition, the coccyx is mobile and during childbirth it is pushed posteriorly, increasing the anteroposterior diameter of the exit of the pelvis, thus facilitating childbirth. When coccyx is fused with sacrum, it becomes fixed. The anteroposterior diameter of exit does not increase, and this may lead to prolonged childbirth and perineal tear ${ }^{1}$.

\section{Conclusion}

We found a high number of sacralization of the lumbar vertebra, diverging from data found in the literature. The importance of the knowledge of such variations should be emphasized on the part of health professionals, especially when performing anesthetic and surgical procedures, promoting a higher rate of success cases. In addition, despite being a benign condition, the variants are related to chronic lumbar pain and disc herniation and should be taken into consideration in the evaluation of the differential diagnosis of radiologists, orthopedists, and other specialists. 


\section{References}

1. Singh R. Classification and analyses of fifth pair of sacral foramina in Indian dry sacra. Int J Morphol. 2014;32(1):125-130.

2. Nastoulis E, Karakasi M-V, Pavlidis P, Thomaidis V, Fiska A. Anatomy and clinical significance of sacral variations: a systematic review. Folia Morphol. 2019;78(4):651-667.

3. Mahato NK. Complexity of neutral zones, lumbar stability and subsystem adaptations: probable alterations in lumbosacral transitional vertebrae (LSTV) subtypes. Med hypotheses. 2013;80(1):61-64.

4. Otani K, Konno S, Kikuchi S. Lumbosacral transitional vertebrae and nerve-root symptoms. J Bone Joint Surg Br. 2001;83(8):1137-1140. 5. Bron JL, van Royen BJ, Wuisman PI. The clinical significance of lumbosacral transitional anomalies. Acta Orthop Belg. 2007;73(6):687-695.

6. Krishnamurthy A, Adibatti M. Study on incidence of sacralisation of fifth lumbar vertebra in South Indian population. Ital J Anat Embryol. 2016;121(1):60-65.

7. Mahato NK. Implications of structural variations in the human sacrum: why is an anatomical classification crucial? Surg Radiol Anat. 2016;38(8):947-954.

8. Vergauwen S, Parizel PM, van Breusegem L, Van Goethem JW, Nackaerts Y, Van den Hauwe L, et al. Distribution and incidence of degenerative spine changes in patients with a lumbo-sacral transitional vertebra. Eur Spine J. 1997;6(3):168-172.

9. Hsieh CY, Vanderford JD, Moreau SR, Prong T. Lumbosacral transitional segments: classification, prevalence, and effect on disk height. J Manipulative Physiol Ther. 2000; 23(7):483-489.

10. Hughes RJ, Saifuddin A. Imaging of lumbosacral transitional vertebrae. Clin Radiol. 2004;59(11):984-991.

11. Bertolotti M. Contributo alla conoscenza dei vizi di differenzazione regionale del rachide con speciale reguardo all assimilazione sacrale della V. lombare. La Radiologia Medica. 1917;4:113-144.

12. Erken E, Ozer HTE, Gulek B, Durgun B. The association between cervical rib and sacralization. Spine. 2002; 27(15):1659-1664.

13. Rizzi KD, Ferraz RRN, Rodrigues FSM, Errante PR, Errante JV, Barnabé AS. Presença de osteófitos, de sacralizacao da quinta vertebra lombar (L5) e de lombarização da primeira vértebra sacral (S1) em sacros humanos isolados ou anexos aos ossos do quadril. Rev UNILUS Ens Pesq. 2015;12(28):15-20.

14. Macêdo BS. Vertebra de transição lombar e alterações degenerativas da coluna lombassacra. Dissertação (Mestrado). 72 f. Universidade Federal de Pernambuco. Programa de Pós-Graduação em Neuropsiquiatria e Ciências do Comportamento. Recife, 2018. 15. Laishram D, Ghosh A, Shastri D. A study on the variations of sacrum and its clinical significance. IOSR J Dent Med Sci. 2016;15(6):8-14.

16. Goswami P, Yadav Y, Chakradhar V. Sacral Foramina: Anatomical Variations and Clinical Relevance in North Indians. Eur J Acad Essays. 2014;1(4);29-33.
17. Chaijaroonkhanarar W, Buranarugsa $M$, Umka J, Namking $M$. Sacralisation of the 5 th lumbar vertebra in Thais. Srinagarind Med J. 2006; 21(3):194-199.

18. Swargam N, Chandrupatla $M$. Sacralisation of fifth lumbar vertebra. Int J Rec Sci Res. 2014;5(6):1159-1160.

19. Breathnach AS. Frazer's anatomy of the human skeleton. 6th ed. London, Churchill Livingstone, 1965.

20. Sadler TW. Langman's Medical Embryology. 11th ed. Philadelphia, Lippincott Williams \& Wilkins, 2010. pp. 142.

21. Sharma VA, Sharma DK, Shukla CK. Osteogenic study of lumbosacral transitional vertebra in central India region. J Anat Soc India. 2011;60(2):212-217.

22. Adibatti M, Asha K. Lumbarisation of the first sacral vertebra a rare form of lumbosacral transitional vertebra. Int J Morphol. 2015:33(1):48-50.

23. Wellik DM, Capecchi MR. Hox10 and Hox11 genes are required to globally pattern the mammalian skeleton. Science. 2003;301(5631):363-367.

24. Eyo MU, Olofin A, Noronha C, Okanlawon A. Incidence of lumbosacral transitional vertebrae in low back pain patients. West Afr J Radiol. 2001;8(1):1-6.

25. Hughes RJ, Saifuddin A. Numbering of Lumbosacral Transitional Vertebra on MRI: Role of the iliolumbar ligaments. AJR Am J Roentgenol. 2006;187(1):W59-65.

26. Wiese M, Krämer J, Bernsmann K, Ernst WR. The related outcome and complication rate in primary lumbar microscopic disc surgery depending on the surgeon's experience: comparative studies. Spine J. 2004;4(5):550-556.

27. Ebraheim NA, Miller RM, Xu R, Yeasting RA. The location of the intervertebral lumbar disc on the posterior aspect of the spine. Surg Neurol. 1997;48(3):232-236.

28. Revuelta R, De Juambelz PP, Fernandez B, Flores JA. Lumbar disc herniation in a $27-$ month old child. Case report J Neurosurg. 2000;92(1):98-100.

29. Nicholson AA, Roberts GM, Williams LA. The measured height of the lumbosacral disc in patients with and without transitional vertebrae. Br J Radiol. 1988;61:454-455.

30. Aihara T, Takahashi K, Ogasawara A, Itadera E, Ono Y, Moriya $\mathrm{H}$. Intervertebral disc degeneration associated with lumbosacral transitional vertebrae: a clinical and anatomical study. J Bone Joint Surg. 2005;87-B:687-691.

31. Aggarwal A, Aggarwal A, Harjeet, Sahni D. Morphometry of sacral hiatus and its clinical relevance in caudal epidural block. Surg Radiol Anat. 2009;31(10):793-800.

32. Kamal AHMM, Ara S, Ashrafuzzaman M, Khatun K, Islam MS. Morphometry of sacral hiatus and its clinical relevance in caudal epidural block. J Dhaka Med Coll. 2014;23(1):31-36.
Received: March 30, 2021

Accepted: April 20, 2021
Corresponding author

Jalles Dantas de Lucena

E-mail: jallesdantas@gmail.com 